\title{
The impact of atmospheric blocking on the compounding effect of ozone pollution and temperature: A copula-based approach
}

\author{
Noelia Otero, Oscar Jurado, Tim Butler and Henning W. Rust
}

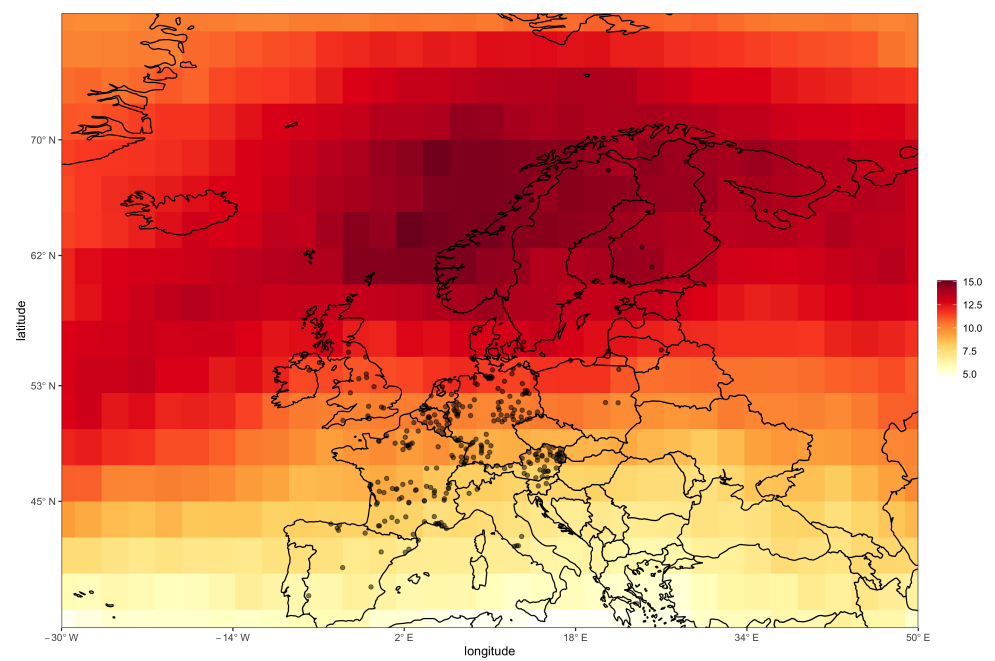

Figure S1. Frequency of atmospheric blocking (\%) during the ozone season (April-September) for the period 1999-2015). Black dots represent the measurement stations used in the study.

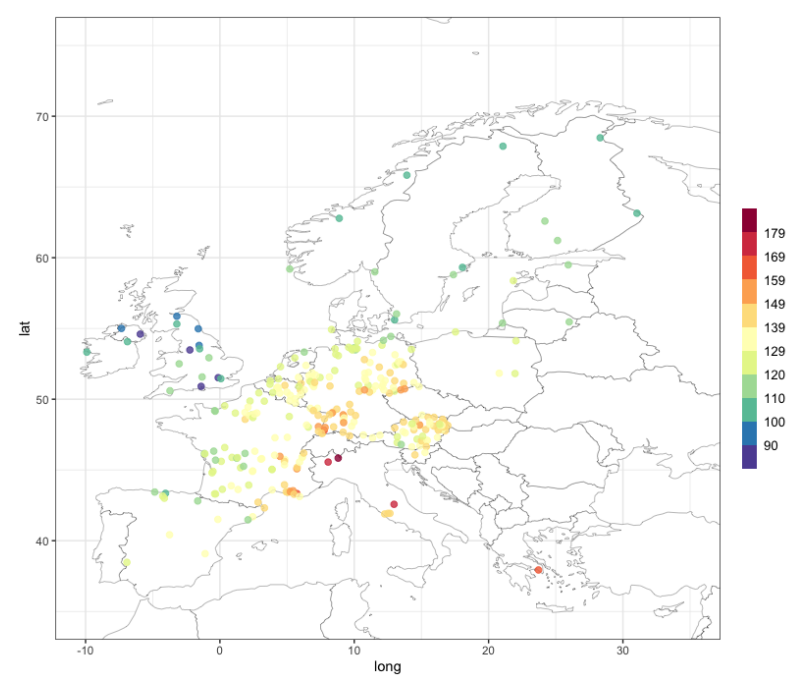

Figure S2. Distribution of the 95th percentile of ozone (MDA8O3) concentrations during the ozone season (April-September) for the period 1999-2015. 


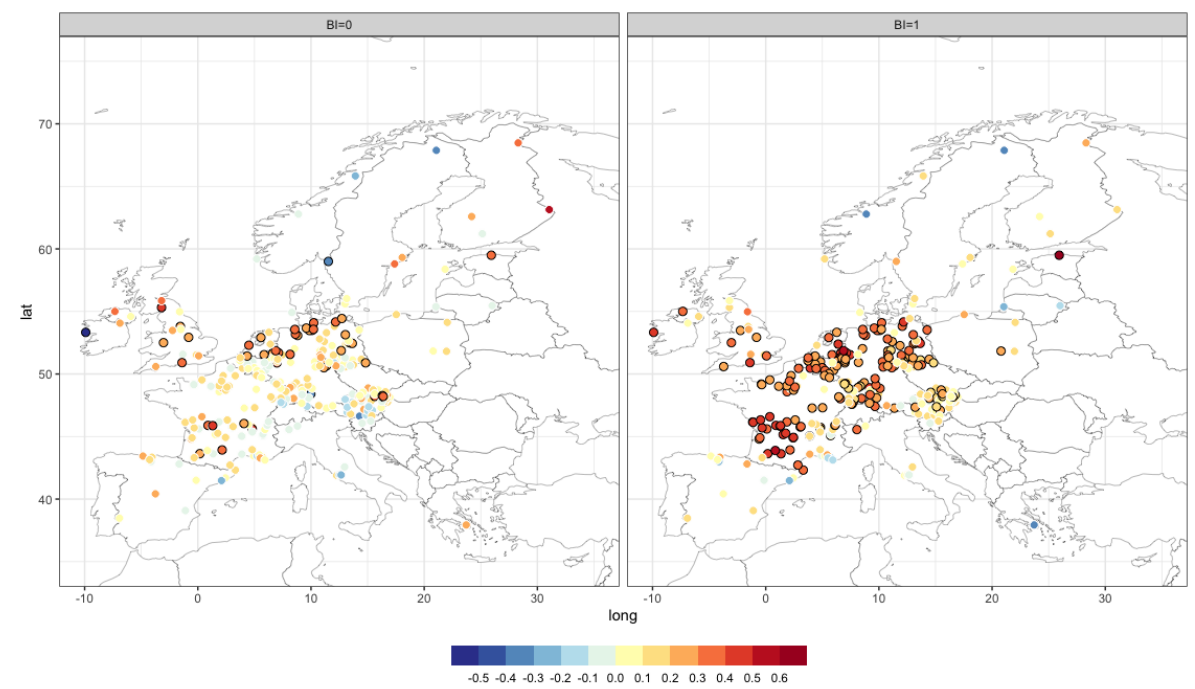

Figure S3. Spatial distribution of the correlation values between ozone and temperature extremes.

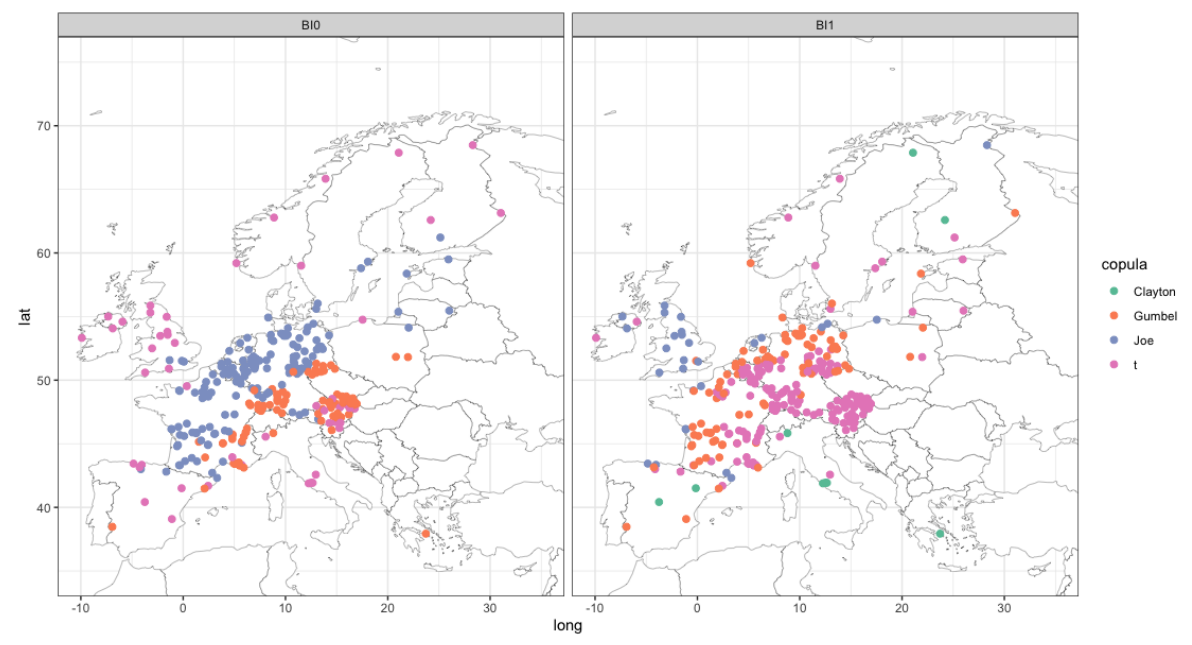

Figure S4. Spatial distribution of the selected copula for non blocking conditions (BI=0, left) and blockgin conditions (right, $\mathrm{BI}=1$ ) 

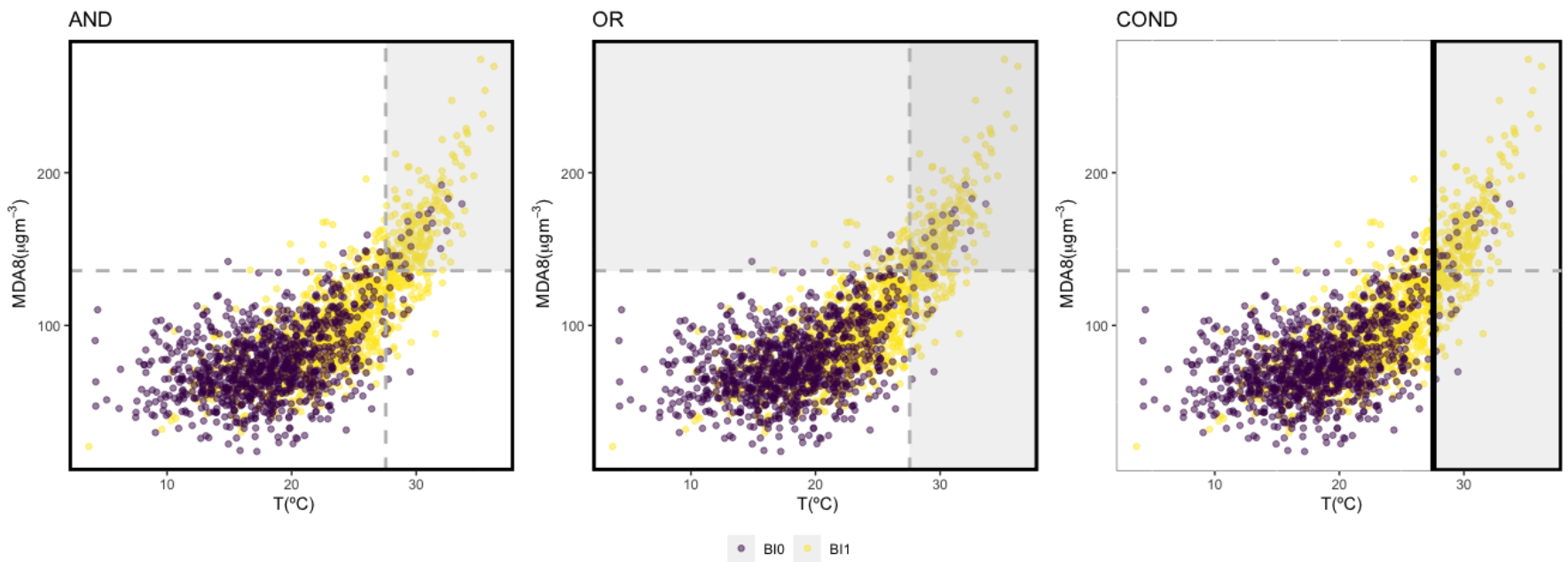

Figure S5. Illustrative example with the probability scenarios used in the study: AND (left), OR (middle), and COND(right). Bold black lines identify the domain where each probability is estimated and the grey areas represent the critical regions associated with the corresponding probability. 